\title{
Health Problems and Health Seeking Behaviour of Hospital Cleaners in a Tertiary Health Facility in South West Nigeria
}

\section{Olayinka S. Ilesanmi}

Department of Community Health, Federal Medical Centre, Owo, Ondo State, Nigeria

Email: ileolasteve@yahoo.co.uk

Bridget A. Omotoso

Olufemi O. Ayodeji

Darlington T. Falana

Department of Community Health, Federal Medical Centre, Owo, Ondo State, Nigeria

Doi:10.5901/ajis.2014.v3n6p187

\begin{abstract}
This study aimed to determine the prevalent health problems and also investigate the health seeking behavior among hospital cleaners of Federal Medical Center, Owo, Ondo State. Nigeria. A cross-sectional study of 249 hospital cleaning staff was conducted. Semi-structured interviewer administered questionnaires were used to obtain information. Descriptive statistics were done and associations were explored with the chi square test at $5 \%$ level of significance. The mean age of respondent was $34 \pm 7$ years, 142(57.0\%) attended secondary school. The workplace health problems of the cleaning staff in the month preceding the study included low back pains $63.1 \%$, muscular and joint pains $38.6 \%$ and skin rashes $14.9 \%, 15.7 \%$ had eye problems. The chronic health problems reported among the cleaners were hypertension $5.6 \%$, asthma (0.8\%) and epilepsy $(0.4 \%)$. Some (3.2\%) of the respondents did not seek healthcare at FMC, Owo because they felt they were not being cared for while $3.6 \%$ believed they were healthy and others $4.4 \%$ believed the services were too expensive. Like other health workers, hospital cleaners as shown in this study, also have health needs which must be met. Services of the hospital can be made available to the cleaners at subsidized costs.
\end{abstract}

Keywords: Health Problems, Health Seeking Behaviour, Hospital, Cleaners.

\section{Introduction}

Health is a very important basic need necessary for both social and economic development; it is an essential ingredient of life desired by everybody irrespective of status, profession, age or background. As defined by the World Health Organization, Health is a state of complete physical, mental, social and spiritual well-being, not merely the absence of disease or infirmity.(Davies, 2005) The hospital cleaners are prone to different health problems and diseases; chief among these, as documented in previous studies, are musculoskeletal disorders like muscular aches, pains and discomfort which may affect the neck, upper limbs and low back.(OECD, 2009, Jütting et al., 2008) The hospital cleaners are also predisposed to respiratory disorders like asthma, bronchitis etc that are common with other cleaning workers. (Lucas and Gilles, 2004, Unge et al., 2007, Tinubu et al., 2010, Omokhodion et al., 2000, Bello et al., 2009) Furthermore, they may also be faced with occupational diseases like Hepatitis B infection, HIVIAIDS and other infections to which other health workers are prone while doing their job.(Imperial College London, 2013, Zock, 2005, Delcos et al., 2006) Skin disorders like dermatitis and psychosomatic disorders have also been reported among hospital cleaners. (Amosu et al., 2011, Medina-Ramon et al., 2005)

In many of the tertiary health facilities in Nigeria cleaning works are contracted to cleaning companies which in turn employ the cleaners to work for them. Out sourcing non clinical services in the hospital is used in the developed countries as well.(Manyele et al., 2008) Though unskilled, the cleaners play a very important role in the workings of the hospital. Though exposed to various hazards and health challenges, the cleaners' health needs are often relegated to the background by their employers. This is not the case only in developing countries like Nigeria; even in developed world, these groups of workers are usually taken into cognizance by legislations, and do not have the luxury of accessing 
available occupational health services which other workers enjoy. (Orji et al., 2002, Ansa et al., 2002, Kirtiganda et al., 2011)

The duties of Hospital cleaners include cleaning of patients' rooms, nursing units, surgical areas, administrative offices, laboratory areas, waiting areas and public restrooms. They also clean furniture, polish floors and vacuum carpets. They empty trash and restock medical supplies. Hospital cleaners also collect dirty laundry from all patient areas and distribute the clean linen and hospital gowns back to the appropriate quarters. Some also take inventory of any repairs or replacements. (Cawkrodger et al., 2006)

Like in any developing country, several factors determine the health seeking behaviour of Nigerian populace of which the cleaners belong. These factors include the severity of the symptoms of illness, Socio-cultural influences, distance, place and cost of treatment, Income, level of education and quality of healthcare facilities.(Tanimola and Julius, 2009)

It is noteworthy that despite the important role these health workers perform in the hospital, less importance is placed on their health needs. This study aimed to determine the prevalent health problems among hospital cleaners of Federal Medical Centre, Owo, Ondo State, Nigeria and also to investigate their health seeking behavior. The findings will be used in designing interventions which will take care of their health needs.

\section{Materials and Method}

This study was carried out at the Federal Medical Center, Owo, located in Owo Local Government Area of Ondo State, Nigeria. The hospital provides healthcare services at the primary, secondary and tertiary levels to the people within its catchment areas which are Ondo, Kogi, Edo, Ekiti and Osun States. It also receives patients from almost all the states of the Federation because it is situated a stone's throw from the highway that links Abuja to Lagos. It is also an approved training center by both the West African Postgraduate College and the National Postgraduate College to train Resident Doctors in some specialist area of Medicine. The centre has 21 clinical and 7 non-clinical departments. It is a 250 bedded tertiary health center. The bed occupancy rate of not less than $70 \%$ at every point in time is the norm. The Staff strength of the hospital is about 1200 with 513 in the clinical departments and units including 213 Doctors and 300 Nurses as at the time of this study.

In Federal Medical Centre, Owo six private companies were in charge of cleaning job. The companies have about 300 cleaning staff. All the cleaning workers were requested to participate in the survey. However, 249 cleaners were available at the time of data collection. A cross-sectional design of all the cleaning staff was conducted using interviewer assisted questionnaire. Services of trained research assistants and Medical Officers were used for data collection. The study instrument was translated from English to Yoruba and then back- translated to English, to retain the original meanings of the words.

Questionnaires were checked for omissions and errors, corrections were made as necessary. Data were analyzed using SPSS version 21.0.

Frequencies, proportions were presented using appropriate charts and tables. Chi-square test was used to assess associations between proportions. Level of statistical significance was at $5 \%$.

\section{Ethical consideration}

Approval for the study was sought and obtained from the Federal Medical Centre, Owo Health Research Ethics Committee. Informed consent was obtained from the respondents, who were made to understand that participation is voluntary and that there was no consequence whatsoever for non-participation or withdrawal at any stage. Information dissemination plan were discussed with the workers.

\section{Limitations}

Some workers were not willing to tell the whole truth about their work practices. We overcame this by giving them adequate information with assurances of strict confidentiality as well as the benefit they will obtain from the study.

\section{Results}

Out of about 300 cleaning staff in the hospital 249 participated giving a response rate of about $83 \%$. The mean age of 
respondent was $34 \pm 7$ years, Age range from 20 - 60 years. Table 1 shows the socio-demographic and occupational characteristics of the respondents. Majority of them were females 230(92.4\%). More than half of the respondents 136(54.6\%) were aged 30-39 years. Married respondents constituted 187(75.1\%), 42(16.9\%) were single. In all, 142(57.0\%) attended secondary school, 23(9.2\%) had tertiary education.

Table 2 shows the workplace health problems of cleaning staff in the month preceding the study. This reveals that 157(63.1\%) had low back pains, 96(38.6\%) had muscular and joint pains; while 37(14.9\%) of the cleaners had skin rashes, 39(15.7\%) had eye problems. The table also shows that $19(7.6 \%)$ of the cleaning workers had symptoms suggestive of Upper Respiratory Tract Infections.

Table 3 shows the chronic health problems among the cleaning staff. It was found that $14(5.6 \%)$ of the respondents had hypertension while 2(0.8\%) had asthma; $6(2.4 \%)$ had yellowness of eyes while 2(0.4\%) had epilepsy. Fig 1 shows the state of health of the cleaners as reported by them. It was found out that the state of health of 196(78.7\%) of them was excellent, 46(18.5\%) good and 7(2.8\%) fair.

With regards to where the cleaners usually obtain healthcare when sick, majority $198(83 \%)$ of them received care in government hospitals; $34(14 \%)$ received care in chemist shops and 8(3\%) in private hospitals. In all, 194(78\%) of the cleaners have gone for medical check-ups before while 55(22\%) have never done that in their lifetime.

Table 4 show the utilization of health services available at FMC, Owo by the cleaning staff. It was found that $100 \%$ of the people with tertiary education used the facility at FMC, Owo whenever they were sick. Among the sociodemographic factors none has a significant association with utilization of healthcare services available at FMC, Owo.

Regarding why respondents did not seek care in FMC, Owo, among those who responded to this question, 8(3.2\%) said "because they don't care for us", 9(3.6\%) said "I am healthy" and 11(4.4\%) said "the services in FMC, Owo is too expensive". The immediate needs of the cleaners are provision of free health services $(50,20.1 \%)$, reduced workload $(4,16 \%)$, and salary increase $(22,8.8 \%)$.

\section{Discussion}

This descriptive study was designed to examine the health problems and health seeking behaviour of hospital cleaners in a tertiary health institution in Southwestern, Nigeria. Female workers accounted for the majority (92.4\%) of the respondents. Other studies have also shown that majority of hospital cleaners are female.(Manyele et al., 2008, Gamperiene et al., 2003) More than half of the cleaners had at least secondary school education. This shows that they were not illiterates.

This study revealed that musculoskeletal problems i.e. muscular pains, joint pains and low back pains were the major health problems found among the respondents. This may not be unconnected with the physical nature of the work the hospital cleaners do. This has been found also in other similar studies among cleaners and other health workers in some health institutions in Australia, America and Southwest, Nigeria. (Tinubu et al., 2010, Omokhodion et al., 2000, Amosu et al., 2011, Smith and Leggat, 2004, Lipscomb et al., 2004) Other health problems recorded among the cleaners which are of utmost importance were skin rashes and asthmatic symptoms. These were also found in some previous studies in America, Britain and Nigeria. (Rosenman et al., 2003, Medina-Ramon et al., 2003, Bello et al., 2009, Imperial College London, 2013, Zock, 2005, Delcos et al., 2006, Orji et al., 2002) The skin lesions may have resulted from insect bite to which these workers are exposed to especially when they are on night shifts while the asthmatic symptoms are due their exposure to dusty particles while doing their work. Other health problems found in this study which were not reported in previous studies include eye problems, burns and upper respiratory infections.

Chronic health problems found among these hospital cleaners are hypertension, epilepsy and asthma. Out of these disorders the only one found reported in similar studies previously was chronic asthma.(Zock et al., 2002, MedinaRamon et al., 2005, Gamperiene et al., 2003) Majority (78.7\%) of the respondents reported their state of health as being excellent. Those who reported their state of health as being good were $18.5 \%$ while $2.8 \%$ had theirs as fair.

Most of the respondents received healthcare in government hospitals while Chemist shops were the next patronized place, a few also utilized private health facilities. This is not the case in a similar study carried out among the people in a University community in Nigeria in which it was found that most people patronize private health facilities.(Tanimola and Julius, 2009) This also disagrees with the finding in another study carried out in a rural community in Southwest Nigeria where it was found out that only $44 \%$ of respondents utilize healthcare facilities when sick. (Sule et al., 2008) Many (78\%) of the cleaning workers had gone for medical check-ups at one time or the other. This may be so because they work in a hospital environment where emphasis is placed on routine medical check-ups. No significant association existed between the socio-demographic factors and utilization of healthcare services at FMC, Owo. 
With regards to the reasons given by the cleaners for not accessing healthcare at FMC, Owo, most of the respondents said that the management of the center did not care for them, others said that the cost of healthcare services were too expensive. Perceived high cost was among the reasons identified for low utilization of healthcare services in Nigeria.(Sule et al., 2008) This however differs from findings in another study among market traders in Ibadan where a belief that illness could not be cured by orthodox medicine, unfriendly health workers and delays in service were factors found to be associated with lack of utilization of available health facilities.(Ige and Nwachukwu, 2009)

\section{Conclusion}

This study supports the need to put in place services to meet the needs of hospital cleaners. Like other health workers, hospital cleaners as shown in this study, also have health needs which must be met by their employers. The main health problems of hospital cleaners in this study were musculoskeletal though some have chronic health problems like asthma and hypertension. High cost of hospital care is a major barrier to the utilization of health facility.

\section{Recommendations}

Health education should be intensified to encourage appropriate health seeking behavior among this group of hospital workers. Adequate arrangements should be made to meet the health needs of the cleaners by their employers. Services of the hospital can be made available to the cleaners at affordable costs.

Table 1: Socio-demographic and Occupational Characteristics of the Respondents

\begin{tabular}{ccc}
\hline Socio-demographic Characteristics & N & $\%$ \\
\hline Age in years & 52 & 20.9 \\
$20-29$ & 136 & 54.6 \\
$30-39$ & 61 & 24.5 \\
$\geq 40$ & & \\
Sex & 19 & 7.6 \\
Male & 230 & 92.4 \\
Female & & \\
Marital Status & 42 & 16.9 \\
Single & 187 & 75.1 \\
Married & 20 & 8.0 \\
Others* & & \\
Primary & 55 & 22.1 \\
Highest Level of Education & 29 & 11.6 \\
Junior Secondary School & 142 & 57.0 \\
Senior Secondary School & 23 & 9.2 \\
Tertiary & &
\end{tabular}

*Others were widowed and divorced

Table 2: Workplace Health Problems of Cleaning Staff in the month preceding the study.

\begin{tabular}{lcc}
\hline Health Problems & Present (\%) & Absent (\%) \\
\hline Skin Rashes & $37(14.9)$ & $212(85.1)$ \\
Eye Problems & $39(15.7)$ & $210(84.3)$ \\
Hearing Problems & $23(9.2)$ & $226(90.8)$ \\
Low Back Pain & $157(63.1)$ & $92(36.9)$ \\
Muscular \& Joint Pain & $96(38.6)$ & $153(61.4)$ \\
Burns & $25(10.0)$ & $224(90.0)$ \\
Injuries & $17(6.8)$ & $232(93.2)$ \\
Symptoms suggestive of URTI & $19(7.6)$ & $230(92.4)$ \\
Symptoms Suggestive of Asthma & $15(6.0)$ & $232(234)$ \\
Symptoms suggestive of STI & $11(4.4)$ & $238(95.6)$ \\
Falls & $9(3.65)$ & $240(96.4)$ \\
Electric Shock & $11(4.4)$ & $238(95.6)$ \\
Needle Pricks & $17(6.8)$ & $232(93.2)$ \\
Nail Infection & $13(5.2)$ & $232(94.8)$ \\
\hline
\end{tabular}


Table 3: Chronic Health problems among the cleaning staff.

\begin{tabular}{lcc}
\hline Chronic Health Problems & Present (\%) & Absent (\%) \\
\hline Hypertension & $14(5.6)$ & $235(94.4)$ \\
Asthma & $2(0.8)$ & $247(99.2)$ \\
Epilepsy & $2(0.8)$ & $247(99.2)$ \\
\hline
\end{tabular}

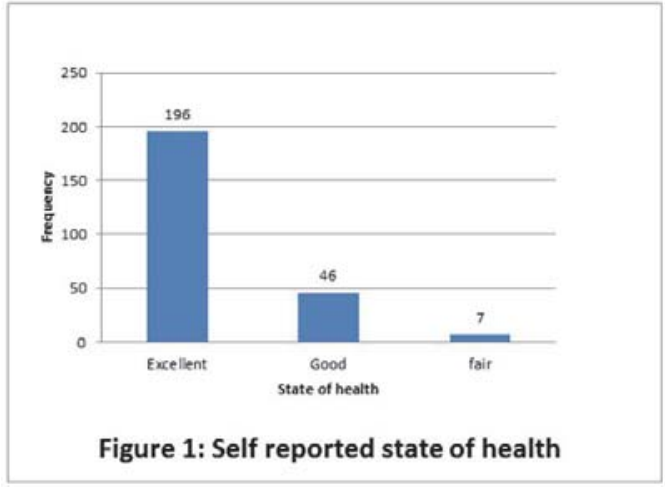

Table 4: Utilization of Healthcare Services available at FMC, Owo

\begin{tabular}{|c|c|c|c|c|}
\hline \multicolumn{5}{|c|}{ Utilization of Healthcare Services available at FMC, Owo } \\
\hline Characteristics & Yes (\%) & No $(\%)$ & $\mathbf{X}^{2}$ & P-Value \\
\hline \multicolumn{5}{|l|}{ Age group in years } \\
\hline $20-29$ & $40(76.9)$ & $12(23.1)$ & 6.44 & 0.40 \\
\hline $30-39$ & 121(89.0) & 15(11.0) & & \\
\hline$\geq 40$ & $47(77.0)$ & 14(23.0) & & \\
\hline \multicolumn{5}{|l|}{ Sex } \\
\hline Male & $16(84.2)$ & $3(15.8)$ & 0.007 & 0.934 \\
\hline Female & 192(83.5) & $38(16.5)$ & & \\
\hline \multicolumn{5}{|l|}{ Religion } \\
\hline Christianity & 182(82.7) & $38(17.3)$ & 0.894 & 0.344 \\
\hline Islam & $26(89.7)$ & $3(10.3)$ & & \\
\hline \multicolumn{5}{|l|}{ Marital Status } \\
\hline Married & 154(82.4) & $33(17.6)$ & 0.943 & 0.624 \\
\hline Single & $36(87.5)$ & $6(14.3)$ & & \\
\hline Others & $18(90.0)$ & $2(10.0)$ & & \\
\hline \multicolumn{5}{|l|}{ Tribe } \\
\hline Yoruba & 184(82.5) & $39(17.5)$ & 1.625 & 0.202 \\
\hline Others & $24(92.3)$ & $2(7.7)$ & & \\
\hline $\begin{array}{c}\text { Highest Level of Education } \\
\text { Primary }\end{array}$ & 45(81.8) & 10(18.2) & 2.196 & 0.334 \\
\hline Junior Secondary & $27(93.1)$ & $2(6.9)$ & & \\
\hline Senior Secondary and above & $136(82.4)$ & $29(17.6)$ & & \\
\hline
\end{tabular}

\section{References}

Hospital Housekeeper: Job Description and Education Requirements http://educationportal.com/articles/Hospital_Housekeeper_ Job_Description_and_Education_Requirements.html. 2013.

AMOSU, A., DEGUn, A., ATULOMAH, N., OLANREWAJU, M. \& ADERIBIGBE, K. 2011. The Level of Knowledge Regarding Occupational Hazards Among Nurses in Abeokuta Ogun State. Nigeria. Current Research Journal of Biological Sciences, 3, 586590.

Ansa, V. O., Udoma, E. J., Umoh, M. S. \& Anah, M. U. 2002. Occupational Risk of Infection by Human Immunodeficiency and Hepatitis B Viruses Among Health Workers in South-West Nigeria. East African Medical Journal, 79, 254-256.

BELLO, A., QUINN, M. M., PERRY, M. J. \& Milton, D. K. 2009. Characterization of Occupational Exposures to Cleaning Products Used for Common Cleaning Tasks- A Pilot Study of Hospital Cleaners. Environ Health., 8. 
Cawkrodger, D. J., Lioyd, M. H. \& Hunter, J. A. 2006. Occupational Skin Disease in Hospital Cleaning an Kitchen Workers. Contact Dermatitis., 15, 132-135.

Davies, S. 2005. Hospital contract cleaning and infection control, London, UNISON

Delcos, G. L., Gimeno, D., Arif, A. A., Burau, K. D., Carson, A., Lusk, C., Stock, T., Symaanski, E., Whithead, L. W., Zock, J. P., Benaivides, F. G. \& Anto, J. M. 2006. Occupational Risk Factors and Asthma Among Healthcare Professionals. Am J Respiratory Crit Care Med. , 175, 667-75.

Gamperiene, M., Nygard, J. F., Brage, S., Bjerkedal, T. \& Brusgard, D. 2003. Duration of Employment is not A Predictor of Disability of Cleaners: A Longutidinal Study. Scandinavian Journal of Public Health, 31, 63-68.

Ige, O. K. \& Nwachukwu, C. C. 2009. Health Care seeking behaviour among market traderrs in Ibarapa Central Local Government, Nigeria. The Internet Journal of Health, 9.

Imperial College London. 2013. CleaningJobs Linked to Asthma Risk [Online]. London. [Accessed March 10, 2014 2014].

Jütting, J., Parlevlie, J. \& Xenogiani, T. 2008. Informal employment re-loaded: OECD Development Centre Working Paper No 266; January.

Kirtiganda, S., Shrawan, K. \& HOOD, J. 2011. Non-Fatal Occupational Injury Rates and Musculoskeletal Symptoms Among Housekeeeping Employees of a Hospital in Texas. Journal of Environmetal and Public Health, 2011, 7.

Lipscomb, J., Trincoff, A., Brady, B. \& Gieger-Brown, J. 2004. Health Care System Changes and Reported Musculoskeletal Disorders among Registered Nurses. AM J Public Health, 94, 1431-1436.

Lucas, A. O. \& Gilles, H. M. 2004. Short Textbook of Public Health Medicine for the Tropics, Great Britain, Arnold.

Manyele, M., Ngonyani, H. \& Eliakim, E. 2008. The status of Occupational Safety Among Health Service Providers in Hospitals in Tanzania. Tanzania Journal of Health Research, 10, 159-165.

Medina-Ramon, M., Zock, J. P., Kogevinas, M., Sunyer, J. \& Anto, J. M. 2003. Asthma Symptoms in Women Employed in Domestic Cleaning: A Community Based Study. Thorax, 58, 950-954.

Medina-Ramon, M., Zock, J. P., Kogevinas, M., Sunyer, J., Torralba, Y., Borrella, A., Burgos, F. \& Anto, J. M. 2005. Asthma, Chronic Bronchitis and Exposure to Irritant Agents in Occupational Domestic Cleaning: A Nested Case-Control Study. Occup Environ Med 62, 598-606.

OECD 2009. Overview:Data on informal employment and self-employment from "Is informal normal? Towards more and better jobs in developing countries [20/01/2013]. Available from: www.oecd.org/dev/employment

Omokhodion, F. O., Umar, U. S. \& Ogunowo, B. E. 2000. Prevalence of Low Back Pain Among Staff in a Rural Hospital in Nigeria. Occup. Med., 50, 107-110.

Orji, E., Fasubaa, O., Onwudiegwu, U., Dare, F. \& Ogunniyi, S. O. 2002. Occupational health hazards among health care workers in an obstetrics and gynaecology unit of a Nigerian teaching hospital. Journal of obstetrics and gynaecology : the journal of the Institute of Obstetrics and Gynaecology., 22, 75-78.

Rosenman, K. D., Reilly, M. J., Schill, D. P., Valiant, D., Flattery, J., Harrison, R., Reinisch, F., Pechter, E., Davis, L., Tumpowsky, C. M. \& Filios, M. 2003. Cleaning Products and Work-Related Asthma. Journal of Occupational and Environmental Medicine, 45, 556563.

Smith, D. R. \& Leggat, P. A. 2004. Musculoskeletal Disorders among Rural Australian Nursing Students. Aust. J Rural Health, 12, 241245.

Sule, S. S., ljadunola, K., Onayade, A. A., Fatusi, A. O., Soetan, R. O. \& Conell, F. A. 2008. A Study on the Utilization of Primary Health Care Facilities in a Rural Community. Nigeria Journal of Medicine 17, 98-106.

Tanimola, M. A. \& JULIUS, O. O. 2009. Health Seeking Behaviour in Anyigba, North-Central, Nigeria. Research Journal of Medical Sciences 3, 47-51.

Tinubu, B. M. S., MBADA, C. E., OYEYEMI, A. L. \& FABUNMI, A. A. 2010. Work-Related Musculoskeletal Disorders Among Nurses in Ibadan, South-West Nigeria: a Cross-Sectional Survey. BMC Musculoskeletal Disorder, 11.

Unge, J., Kerstina, O., Catarina, N., Gert-Ake, H., Staffan, S. \& Istvan, B. November 2007. Differences in Physical Workload, PsychoSocial Factors and Musculoskeletal Disorders Between Two Groups of Female Hospital Cleaners With Two Diverse Organizational Models. International Archives of Occupational and Environmental Health, 81, 209-220.

W H O World Health Organization and international Labour Organization 2000,WHO-ILO joint effort on Occupational health and Safety in Africa; Occupational Health for workers in the informal sector:; 2000.

Zock, J. P. 2005. World at work: Cleaners. Occup. Environ Med, 62, 581-548.

Zock, J. P., KOGEVINAS, M., SUNYER, J., TOREN, K. \& ANTO, J. M. 2002. Asthma Characteristics in Cleaning Workers, Workers in Other Risk Jobs and Office Workers. Eur Respir J 679-685. 